\title{
Tethered balloon measurements of biogenic volatile organic compounds at a Boreal forest site
}

\author{
C. Spirig ${ }^{1,2}$, A. Guenther ${ }^{2}$, J. P. Greenberg ${ }^{2}$, P. Calanca ${ }^{1}$, and V. Tarvainen ${ }^{3}$ \\ ${ }^{1}$ Swiss Federal Research Station for Agroecology and Agriculture, Zürich, Switzerland \\ ${ }^{2}$ National Center for Atmospheric Research, Boulder, USA \\ ${ }^{3}$ Finnish Meteorological Institute, Helsinki, Finland
}

Received: 8 September 2003 - Published in Atmos. Chem. Phys. Discuss.: 24 October 2003

Revised: 17 January 2004 - Accepted: 26 January 2004 - Published: 6 February 2004

\begin{abstract}
Measurements of biogenic volatile organic compounds (VOCs) were performed at Hyytiälä, a Boreal forest site in Southern Finland as part of the OSOA (origin and formation of secondary organic aerosol) project in August 2001. At this site, frequent formation of new particles has been observed and the role of biogenic VOCs in this process is still unclear. Tethered balloons served as platforms to collect VOC samples within the planetary boundary layer at heights up to $1.2 \mathrm{~km}$ above ground during daytime. Mean mixed layer concentrations of total monoterpenes varied between 10 and $170 \mathrm{pptv}$, with $\alpha$-pinene, limonene and $\Delta^{3}$ carene as major compounds, isoprene was detected at levels of 2-35 pptv. A mixed layer gradient technique and a budget approach are applied to derive surface fluxes representative for areas of tens to hundreds of square kilometres. Effects of spatial heterogeneity in surface emissions are examined with a footprint analysis. Depending on the source area considered, mean afternoon emissions of the sum of terpenes range between 180 and $300 \mu \mathrm{g} \mathrm{m}^{-2} \mathrm{~h}^{-1}$ for the period of 2-12 August 2001. Surface fluxes close to Hyytiälä were higher than the regional average, and agree well with mean emissions predicted by a biogenic VOC emission model. Total rates of monoterpene oxidation were calculated with a photochemical model. The rates did not correlate with the occurrence of new particle formation, but the ozone pathway was of more importance on days with particle formation. Condensable vapour production from the oxidation of monoterpenes throughout the mixed layer can only account for a fraction of the increase in aerosol mass observed at the surface.
\end{abstract}

Correspondence to: C. Spirig

(christoph.spirig@fal.admin.ch)

\section{Introduction}

The biosphere and plants in particular release a variety of reactive volatile organic compounds (VOCs) that are of importance for atmospheric chemistry. Among the major biogenic emissions are those of monoterpenes, $\mathrm{C}_{10}$-compounds that are readily oxidized in the atmosphere by $\mathrm{OH}-, \mathrm{NO}_{3}-$ radicals or ozone. Several products of these reactions are of low volatility and partition between gas and particulate phases and accordingly may contribute to organic aerosol mass. Through this pathway of secondary organic aerosol (SOA) formation, biogenic VOCs are estimated to significantly add to the load of aerosols on a global scale (Griffin et al., 1999).

Various smog chamber studies have proven the potential of monoterpenes to form aerosols upon oxidation (Hoffmann et al., 1997; Kamens et al., 1999). Several field studies have also indicated the links between the oxidation of biogenic VOCs and formation of organic aerosol under environmental conditions (Kavouras et al., 1998; Kavouras et al., 1999; Leaitch et al., 1999). While it seems clear that biogenic VOC contribute to organic aerosol mass, their role in the process of new particle formation is still uncertain, however. There is also evidence from observations that monoterpene oxidation products are linked to growth rather than to new formation of particles (Janson et al., 2001).

At Hyytiälä, a Boreal forest site in Southern Finland, extensive particle measurements have been carried out in recent years and formation of new particles has been observed on a regular basis (Kulmala et al., 2001; Mäkelä et al., 1997). These nucleation events are postulated to occur on a large horizontal scale on the order of hundreds of $\mathrm{km}$, as they were detected simultaneously at sites that are more than one hundred $\mathrm{km}$ distant (Nilsson et al., 2001).

In summer 2001, we participated in a field campaign at Hyytiälä as part of the EU project, OSOA (origin and formation of secondary organic aerosol formation). The aim of this 
project was to quantitatively understand the sources and formation mechanisms of secondary organic aerosols with both laboratory and field experiments.

In order to judge the impact of biogenic VOCs during particle formation events, one important piece of information is the quantification of their surface flux. Past measurement efforts at the site confirmed the emission of various biogenic VOCs, monoterpenes in particular, with the use of chamber and micrometeorological gradient techniques (Janson et al., 2001; Rinne et al., 2000; Spanke et al., 2001). As a result of these studies, monoterpene emissions close to the SMEAR II site could be characterized. However, it is desirable to verify larger scale fluxes with measurements as well. This is of particular interest for biogenic VOC fluxes at the Hyytiälä site since the particle formation events are believed to occur on a large spatial scale. This work aims to determine if the VOC fluxes on a larger scale are consistent with those near the tower. For this purpose, we performed VOC measurements throughout the atmospheric boundary layer (up to about $1 \mathrm{~km}$ above ground) using a tethered balloon sampling platform. From these measurements we derive surface flux estimates representative for areas of tens to hundreds of square kilometres by means of a gradient method and a boundary layer budget approach.

\section{Experimental}

\subsection{Site description}

The experiment took place in Southern Finland at Hyytiälä $\left(61^{\circ} 51^{\prime} \mathrm{N}, 24^{\circ} 17^{\prime} \mathrm{E}, 181 \mathrm{~m}\right.$ asl), a research site operated by University of Helsinki (SMEAR II, Station for Measuring Forest Ecosystem-Atmosphere Relations). The station is surrounded by Boreal coniferous forest, dominated by Scots pine (Pinus sylvestris) and Norway spruce (Picea abies). According to landuse data encompassing $20 \times 20 \mathrm{~km}$ around the station, $72 \%$ of the surface is covered with forest (Fig. 1). Water bodies (12\%), open fields (10\%) and clear cuts account for most of the remainder. Of the forest area, 37\% is pine dominated, $16 \%$ by spruce, $18 \%$ is covered by deciduous forest and the remainder is mixed coniferous and broadleaf forest (29\%). There is no major source of anthropogenic trace gases nearby; the nearest city is Tampere, located $50 \mathrm{~km}$ in the South-western direction. The terrain around the site exhibits only modest terrain height variation, with $95 \%$ of the area within $20 \times 20 \mathrm{~km}$ between 100 and $220 \mathrm{~m}$ a.s.l. Satellite databases were used to examine the vegetation characteristics of a region extending over $50 \mathrm{~km}$ in each direction from the Hyytiälä site. The databases quantify the spatial distribution of broadleaf and needleleaf tree densities (Defries et al., 2000) and general landcover (Hansen et al., 2000). Both databases have a $1 \mathrm{~km}^{2}$ resolution and were derived from Advanced Very High Resolution Radiometer (AVHRR) satellite observations. These data indicate that this region is fairly homogeneous on a spatial scale of about 5-10 km except that for a radius of about 30 to $40 \mathrm{~km}$ around Hyytiälä, the mainly forested area is interrupted by a fragmented belt of narrow lakes, after which there is an increasing density of water bodies, especially in the southern and northern sectors.

At SMEAR II, aerosols size distribution, gaseous pollutants $\left(\mathrm{SO}_{2}, \mathrm{O}_{3}\right.$ and $\left.\mathrm{NO}_{x}\right)$ and (micro) meteorological parameters have been measured on a routine basis for several years. The sensors are installed at several levels on a $67 \mathrm{~m}$ high tower, located $0.8 \mathrm{~km}$ northeast of the research site buildings. The tethered balloons were launched from a soccer field next to these buildings, about $100 \mathrm{~m}$ east of a lake (Fig. 1).

\subsection{Measurements by tethered balloons}

Two $9 \mathrm{~m}^{3}$ helium balloons (Blimp Works, Statesville, NC) served as platforms to collect VOC samples and meteorological data at heights between $100 \mathrm{~m}$ and $1.3 \mathrm{~km}$ above ground. Three tether lines and winch systems were employed during the campaign. Two were commercially available electric winches (model TS-3-AW, Air Instrumentation Res. Inc., now Vaisala, Boulder CO) that can either be operated with a $12 \mathrm{~V} \mathrm{DC}$ car battery or on AC-power. The lines on these winches were of $700 \mathrm{~m}$ and $800 \mathrm{~m}$ length, respectively. A third system, with a $1500 \mathrm{~m}$ line, was a custom built spool driven by an electric drill.

\subsubsection{Sample collection and meteorological measurements}

VOCs were collected using miniaturized sampling packages that were attached at several different points on the tether line (for a detailed description, see Greenberg et al., 1999a). They are operated by timers and provide flow controlled air sampling onto adsorbent cartridges (adsorbent was a two-stage combination of Carbotrap ${ }^{\circledR}$, and Carbosieve S-III ${ }^{\circledR}$ by Supelco, Inc., Bellefonte, Pennsylvania). The flow rates were $200 \mathrm{ml} \mathrm{min}^{-1}$ yielding sampling volumes between 6 and 101 for pumping times between 30 and $50 \mathrm{~min}$. In addition to collecting trace gases on cartridges, the packages also record pressure, temperature and humidity, all of them recorded with a sampling rate of $0.5 \mathrm{~Hz}$ (Honeywell sensing control model HIH-3602-C). In front of the cartridge, glass wool filters (Acrodisc, Pall Corp., Ann Arbor, MI) soaked with potassium iodide were installed in order to remove ambient ozone and avoid VOC losses through reaction with ozone (Helmig, 1997). In the week before the experiment, cartridges were purged with helium (quality of $>0.99995 \% \mathrm{v} / \mathrm{v}$ ) at $300^{\circ} \mathrm{C}$ for approximately $20 \mathrm{~h}$ and subsequently stored at $\sim-30^{\circ} \mathrm{C}$. At Hyytiälä, cartridges were in a freezer at $\sim-10^{\circ} \mathrm{C}$, during transport to and from Finland (approximately $20 \mathrm{~h}$ ) the cartridges were kept in an ice chest $\left(0-5^{\circ} \mathrm{C}\right)$. All samples were stored at $-30^{\circ} \mathrm{C}$ and analyzed within 30 days after the experiment. Keeping the cartridges at low temperatures after sampling ensures stability of the absorbed VOCs, as verified by storage experiments (Greenberg et al., 1999a). 


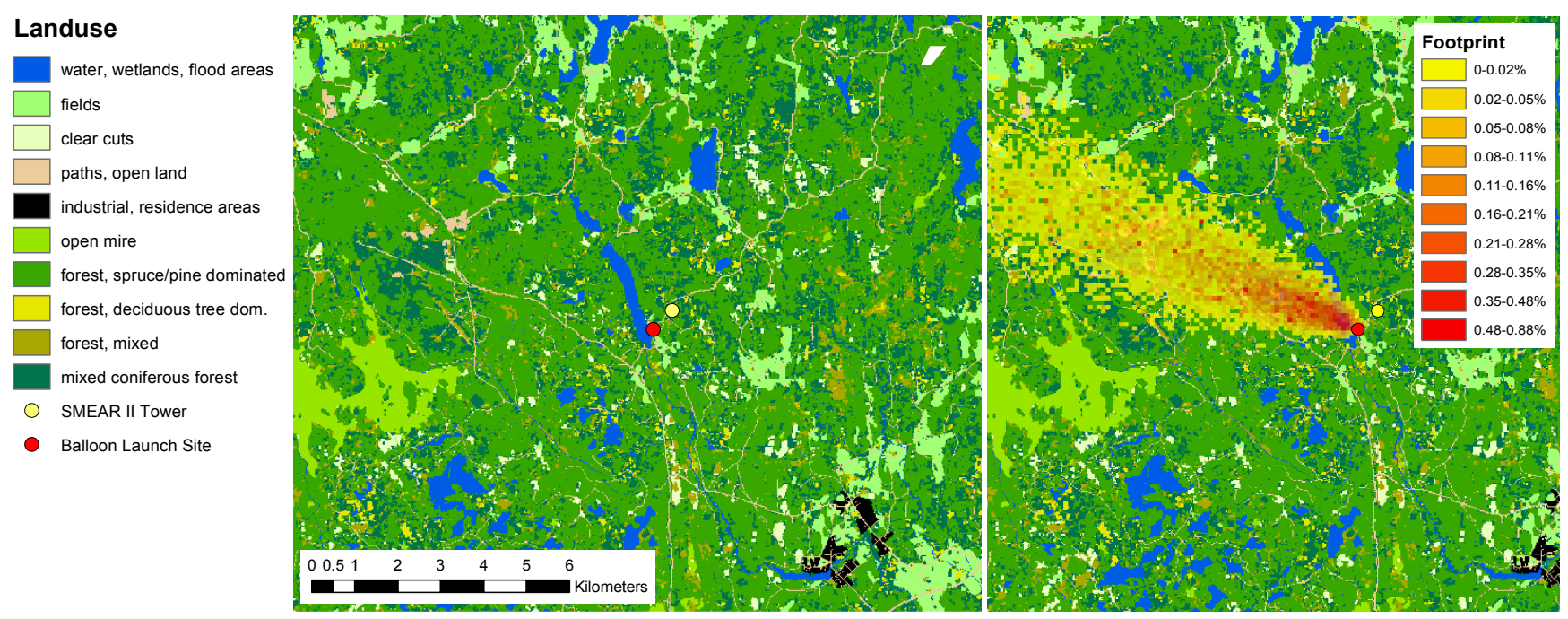

Fig. 1. Land cover around the SMEAR II site at Hyytiälä and visualization of a typical footprint for a 30 min measurement on the tethered balloon (3.8.2001, 13:00, at $150 \mathrm{~m}$ above ground level).

The sampling packages were attached to the tether line in two configurations. (1) Setup for integrative VOC measurement with one package right below (1-2 m) the balloon, operating during ascent and descent. This arrangement delivers temperature and humidity profiles, and an integrative VOC measurement from ground to the maximum height sampled. The tether line was released at typical speeds of $0.5-1 \mathrm{~ms}^{-1}$, resulting in a vertical resolution of the temperature and humidity measurements of 1-2 m. (2) Profile setup, three VOC sampling packages are attached at different positions on the line, at $200 \mathrm{~m}$ (distance from the winch), $400 \mathrm{~m}$, and 700 or $800 \mathrm{~m}$ (depending on whether the 700 or $800 \mathrm{~m}$ line was applied). Typical measurement altitudes of this setup were 100-150 m, 200-300 m, and 500-700 m, whereas higher wind speeds caused lower altitudes as a result of the descent of the balloon. The packages sampled air at those heights during $30 \mathrm{~min}$, delivering a mean VOC profile of the lowest $500-700 \mathrm{~m}$.

The two flight configurations were applied interchangeably for a total of up to 10 flights per day. An exception to this schedule was the afternoon of 7 August, when two balloons (one of each configuration) were operated simultaneously.

Altitudes were determined from pressure data recorded during sampling. The pressure and temperature sensors of each sampler package were run on ground for several minutes every day. These test runs delivered the reference pressure for the determination of the altitudes in flight configuration 2). The comparison of the samplers' temperature and pressure readings with the official meteorological measurements in the SMEAR II station revealed deviations of the lightweight sensors of $\pm 10 \%$, differences that are within the range of the accuracy claimed by the manufacturer (tempera- ture $+/-3.0^{\circ} \mathrm{C}$ at $25^{\circ} \mathrm{C}, \mathrm{RH}+/-5 \%$ at $0-60 \% \mathrm{RH},+/-8 \%$ at $90 \% \mathrm{RH}$, linearity $+/-0.5 \% \mathrm{RH}$ typically). The deviations of the single sensors compared to the SMEAR II reference stayed constant throughout the 10-day period of the measurements. Both pressure and temperature data of the samplers were only used in a relative way and not as absolute measurements. The overall uncertainty of the height determination is therefore limited to the variability associated with up and downdrafts of the balloon during sampling, rather than limited by sensor precision. The accuracy of height measurements is estimated to be within $20 \mathrm{~m}$. Similarly, the limited accuracy of temperature sensors does not allow precise temperature measurements, but does allow detection of temperature gradients.

\subsubsection{Analysis of VOC samples}

The contents of the adsorbent cartridges were analysed by a gas chromatograph with a mass spectrometry detector (GCMS, Hewlett Packard model HP5890/5972). Transfer of the samples onto the chromatographic column $(30 \mathrm{~m} \times 0.32 \mathrm{~mm}$ I.D., $1 \mu \mathrm{m}$-film DB1-column, J\&W Scientific, Folsom, CA) was achieved by an automated inlet system described in detail by Greenberg et al. (1996, 1999a). The key steps can be summarized as follows: water trapped during sampling is first removed by purging with helium at $40^{\circ} \mathrm{C}$. VOCs are then desorbed from the cartridge at $325^{\circ}$ (purge flow of 20 $30 \mathrm{ml} \mathrm{min}{ }^{-1} \mathrm{He}$ for $30 \mathrm{~min}$ ), and focused in a cryogenic freeze-out loop $(2 \mathrm{~mm} \mathrm{ID} \times 100 \mathrm{~mm}$ length stainless steel tubing packed with $60 / 80$ mesh glass beads). Finally, the cryotrap is rapidly heated to $150^{\circ} \mathrm{C}$ and the sample is transferred onto the column, which is held at $-50^{\circ}$ for $2 \mathrm{~min}$ after injection, then heated to $200^{\circ} \mathrm{C}$ at $4^{\circ} \mathrm{C} \mathrm{min}^{-1}$. Due to 
the low VOC concentrations encountered in the experiment, the detector was operated in selective ion mode. Isoprene and terpenes were quantified with respect to a laboratory prepared standard of $10 \mathrm{ppb}$ camphene and $11 \mathrm{ppb}$ isoprene (custom made by E. Apel, NCAR, Boulder $\mathrm{CO}$ ). The mixing ratio of this cylinder was confirmed by GC-FID analysis relative to a primary standard with $201 \mathrm{ppb}$ 2,2-dimethylbutane from the National Institute of Standards and Technology (Boulder, $\mathrm{CO}$ ). Isoprene was quantified from $\mathrm{m} / \mathrm{z} 67$ and monoterpenes from $\mathrm{m} / \mathrm{z}$ 93. Details about the determination of response factors for individual monoterpenes are described in Greenberg et al. (in press).

Runs with the laboratory standard were performed daily, by collecting volumes of $500-1000 \mathrm{ml}$ onto identical cartridges as used in the field experiment. Several halogenated hydrocarbons were introduced into each sample as internal standards, to allow for the estimation of any variations in mass spectrometer sensitivity: chloropropane, which eluted just after isoprene, and 3-fluorotoluene and decahydro-naphthalene (decalin), which elute before and after monoterpenes, respectively. Detection limits for the biogenic VOCs were approximately 1 part per trillion by volume (ppt). The accuracy is ultimately determined by the confidence of the primary standard, which was $+/-5 \%$. Considering uncertainties during sampling and storage as mentioned above, measurement precision for isoprene at $50 \mathrm{ppt}$ was $20 \mathrm{ppt}$; for $\alpha$-pinene, the precision at $200 \mathrm{ppt}$ was $50 \mathrm{ppt}$.

\subsection{Flux calculation methods}

Concentration measurements of monoterpenes and isoprene at different heights within the boundary layer are used to derive corresponding surface fluxes. We applied two methods, a technique deducing surface fluxes of a scalar from its mixed layer gradient and a boundary layer budget approach.

\subsubsection{Mixed layer gradient technique (MLG)}

Gradient methods have widely been applied to determine fluxes from measurements within the surface layer. The flux is described by analogy to molecular diffusion as the product of a gradient and a diffusion coefficient, whereas it is a turbulent exchange coefficient rather than a diffusion coefficient in the case of surface layer gradient theory. In similar genre, Wyngaard and Brost (1984) proposed a flux gradient relationship for the mixed layer, where the mixed layer encompasses that part of the convective boundary layer (CBL) dominated by convective eddies whose scales are comparable to the depth of the entire CBL:

$\frac{\partial C}{\partial z}=-g_{b}\left(\frac{z}{z_{i}}\right) \frac{\overline{w c_{0}}}{z_{i} w *}-g_{t}\left(\frac{z}{z_{i}}\right) \frac{\overline{w c_{z_{i}}}}{z_{i} w *}$,

with $w *$ denoting the convective velocity scale within the $\mathrm{CBL}\left(w *=\left(g\left(\overline{\left.w \theta_{v}\right)}\right)_{0} z_{i} / \theta_{v 0}\right)^{\frac{1}{3}}\right), \overline{\left(w \theta_{v}\right)_{0}}$ is the surface virtual temperature flux, $z_{i}$ the depth of the $\mathrm{CBL}, \overline{w c_{0}}$ and $\overline{w c_{z_{i}}}$ are the turbulent scalar surface and entrainment fluxes, respectively, $z$ is the altitude above ground, $C$ is the mean scalar mixing ratio, and $g_{b}$ and $g_{t}$ are dimensionless bottom-up and top-down gradient functions of height within the CBL.

Moeng and Wyngaard $(1984,1989)$ determined the gradient functions from large eddy simulations of scalar transport within the CBL. From the results of these simulations, Davis (1992) derived following fits for the gradient functions:

$g_{b}=0.4 \cdot\left(\frac{z}{z_{i}}\right)^{-\frac{3}{2}}$ and $g_{t}=0.7 \cdot\left(1-\frac{z}{z_{i}}\right)^{-2}$

More recently, Patton et al. (2003) introduced a modified bottom-up gradient function $\left(g_{b}=0.75\left((z-d) / z_{i}\right)^{-0.8}\right.$ with $d$ being the displacement height) to account for the effect of vegetation canopies on mixing of scalars within the CBL. Given these gradient functions $g_{b}$ and $g_{t}$, and measurements of CBL depth $z_{i}$ and the convective velocity scale, two unknowns remain in Eq. (1), the surface and entrainment flux. Being interested in the surface flux, one can integrate and resolve the equation if the concentration gradients over two height intervals are known, or, alternatively if only one value for $\partial C / \partial z$ and the entrainment flux are known. The latter can be estimated by a simple jump model, describing the entrainment as the product of the concentration difference ("jump") across the boundary layer top and the entrainment rate:

$\overline{w c_{z_{i}}}=-w_{e}\left(C_{M L}-C_{b g}\right)$

$C_{M L}$ and $C_{b g}$ are the mean concentrations of the scalar in the upper mixed layer (ML) and the atmosphere above the ML (background), respectively. The entrainment velocity $\left(w_{e}\right)$ is the rate at which air is drawn into the ML from above, and can be determined from observations of mixed layer depth growth.

The calculation of scalar surface fluxes by the MLG technique therefore requires the scalar concentrations at two or more heights within the CBL, information about the strength of convective mixing $(w *)$, and the CBL depth. Measurements with the tethered balloon provide mixed layer concentrations and the height of the convective boundary layer. Values for $w *$ are calculated from measurements of potential temperature fluxes at the SMEAR II tower. Finally, surface fluxes for single VOC profiles collected at Hyytiälä are obtained by fitting the MLG equation to the measured concentrations with a least square method.

When applying the MLG technique for flux estimates, the validity of the MLG assumptions needs careful evaluation (Davis et al., 1994; Guenther et al., 1996; Helmig et al., 1998). In short, the critical requirements are 1) Sufficiently rapid convective mixing for maintaining a quasi-steady profile, i.e. convective turnover time $\left(z_{i} / w *\right)$ is smaller than variations in surface heat flux and convective layer growth. 2) Lifetime of species is large compared to the timescale of vertical mixing. 3) Sufficient integration time of concentration measurements in order to average over at least a few eddies. 
Finally, MLG theory assumes a horizontally homogenous system, implying spatial homogeneity in emissions and vertical mixing.

In typical midday conditions at Hyytiälä, convective turnover times were about $10-15 \mathrm{~min}\left(z_{i}=1200-1600 \mathrm{~m}\right.$, $\left.w *=1.5-2 \mathrm{~ms}^{-1}\right)$. This turnover time is sufficiently short compared to the timescale of midday variations in mixed layer depth, as well as to the lifetime of most biogenic VOCs. During the increase of the CBL in the morning, however, the changes in surface heat flux may occur on a comparable time scale as $z_{i} / w *$ and profiles during these times may not be suitable for MLG calculations. The sampling time of 30 minutes in the profile measurements is long enough to represent a mean mixed layer gradient and should be sufficient to encompass several eddies.

\subsubsection{Mixed box technique (MB)}

In this budget approach, the convective boundary layer is treated as a well-mixed box. A simplified conservation equation for the mean scalar in this box can be written as

$\frac{\partial C}{\partial t}=-U \frac{\partial C}{\partial x}+\frac{\overline{w c_{0}}-\overline{w c_{z_{i}}}}{z_{i}}+S$.

$C$ is the mean scalar mixing ratio, $U$ is the mean horizontal wind, $\partial C / \partial x$ is the local concentration gradient along the mean horizontal wind direction, $\overline{w c_{0}}$ and $\overline{w c_{z_{i}}}$ are the turbulent fluxes at the surface and at the top of the mixed layer $\left(z_{i}\right)$, respectively. The term $S$ denotes either a sink or source of the scalar in the mixed box. This representation neglects turbulent horizontal advection and mean vertical advection, and premises a linear vertical flux profile in the mixed layer. All these assumptions are commonly satisfied in the well-mixed convective boundary layer (Guenther et al., 1996). Resolving this equation for the surface flux yields

$\overline{w c_{0}}=\overline{w c_{z_{i}}}+z_{i}\left(\frac{\partial C}{\partial t}+U \frac{\partial C}{\partial x}-S\right)$

To calculate the surface flux of biogenic VOCs, we assume their concentration has reached a steady state $(\partial C / \partial t=0)$, is homogenous in space $(\partial C / \partial x=0)$, and that the entrainment flux can be neglected. The surface flux is then given by the product of $z_{i} \cdot S$, whereas $S$ is the total loss rate due to chemical reactions in this case.

We briefly address the relevance of these mixed box assumptions here, a more detailed discussion is provided by Guenther et al. (1996). Neglecting the entrainment flux results in an underestimate of the actual surface flux, whereas the effect of omitting horizontal advection cannot be uniquely qualified. However, the magnitude of both terms can usually be estimated from the balloon profiles. Entrainment fluxes can be assessed with help of the jump model (Eq. 3), and the temporal variations in mean mixed layer concentrations throughout the day provide an estimate for the importance of horizontal advection.
The overall uncertainty associated with box model flux estimates is usually dominated by the uncertainty in quantifying the chemical sink term. For biogenic VOCs, the total loss rate during daytime can be approximated by the sum of their reactions with $\mathrm{OH}-, \mathrm{NO}_{3}$-radicals and ozone $\left(\mathrm{O}_{3}\right)$.

The final equation for calculating the flux of a particular VOC is then

$\overline{w c_{0}}=z_{i} \cdot[\mathrm{VOC}] \cdot\left(k_{\mathrm{OH}} \cdot[\mathrm{OH}]+k_{\mathrm{O}_{3}} \cdot\left[\mathrm{O}_{3}\right]+k_{\mathrm{NO}_{3}} \cdot\left[\mathrm{NO}_{3}\right]\right)$

with $k_{\mathrm{OH}}, k_{\mathrm{O}_{3}}$ and $k_{\mathrm{NO}_{3}}$ being the second order rate coefficients of the VOC with $\mathrm{OH}, \mathrm{O}_{3}$, and $\mathrm{NO}_{3}$, respectively. The surface flux calculation by the MB method therefore requires measurements of the boundary layer depth and the mean concentration in the mixed layer, as well as estimates for the total chemical loss rates of VOCs.

\subsection{Photochemical Model}

Chemical VOC degradation within the mixed layer was quantified with a photochemical box model. The chemical mechanism of the model consists of about 3340 gas phase reactions among 1200 species, as described by Aumont et al. (1999) and Hauglustaine et al. (1999). Photolysis rates are calculated with the tropospheric ultraviolet-visible (TUV 4.1) model (Madronich and Flocke, 1999). An albedo of $10 \%$ was assumed for these calculations and total ozone columns (310-340 Dobson Units) were taken according to data of the NASA Earth Probe TOMS satellite.

As in previous applications of the model for planetary boundary layer (PBL) cases (Greenberg et al., 1999b; Karl et al., 2002), entrainment of air during the growth of the PBL was represented as a first-order source or sink for chemical species in the PBL, depending on the concentration difference between background and PBL

$\frac{d C_{P B L}}{d t}$ entrainment $=-k_{\text {entrainment }}\left(C_{P B L}-C_{b g}\right)$

$C_{P B L}$ is the concentration of the species in the PBL, $C_{b g}$ is the concentration above the PBL (background), first-order rate constants $k_{\text {entrainment }}(>0$ during growth of the PBL and zero at all other times) were chosen specifically for each day, derived from maximum PBL heights and duration of PBL growth. Background concentrations $C_{b g}$ were kept constant with time and set to zero for all VOCs with tropospheric lifetimes shorter than $5 \mathrm{~h}$ (corresponding to simple dilution during PBL growth).

Measurements of $\mathrm{O}_{3}, \mathrm{NO}_{x}$, VOCs, and radiation are used to constrain the box model. For this purpose, biogenic VOC concentrations are taken from the balloon measurements, anthropogenic VOCs are set to mean concentrations as measured on the tower during the second week of the experiment or as reported in earlier campaigns at this site (Janson et al., 2001; Spanke et al., 2001); measured total non-methane VOC levels were below 5 ppb. Ozone and $\mathrm{NO}_{\mathrm{x}}$ levels are constrained to the half hourly measurements at $67 \mathrm{~m}$ above 


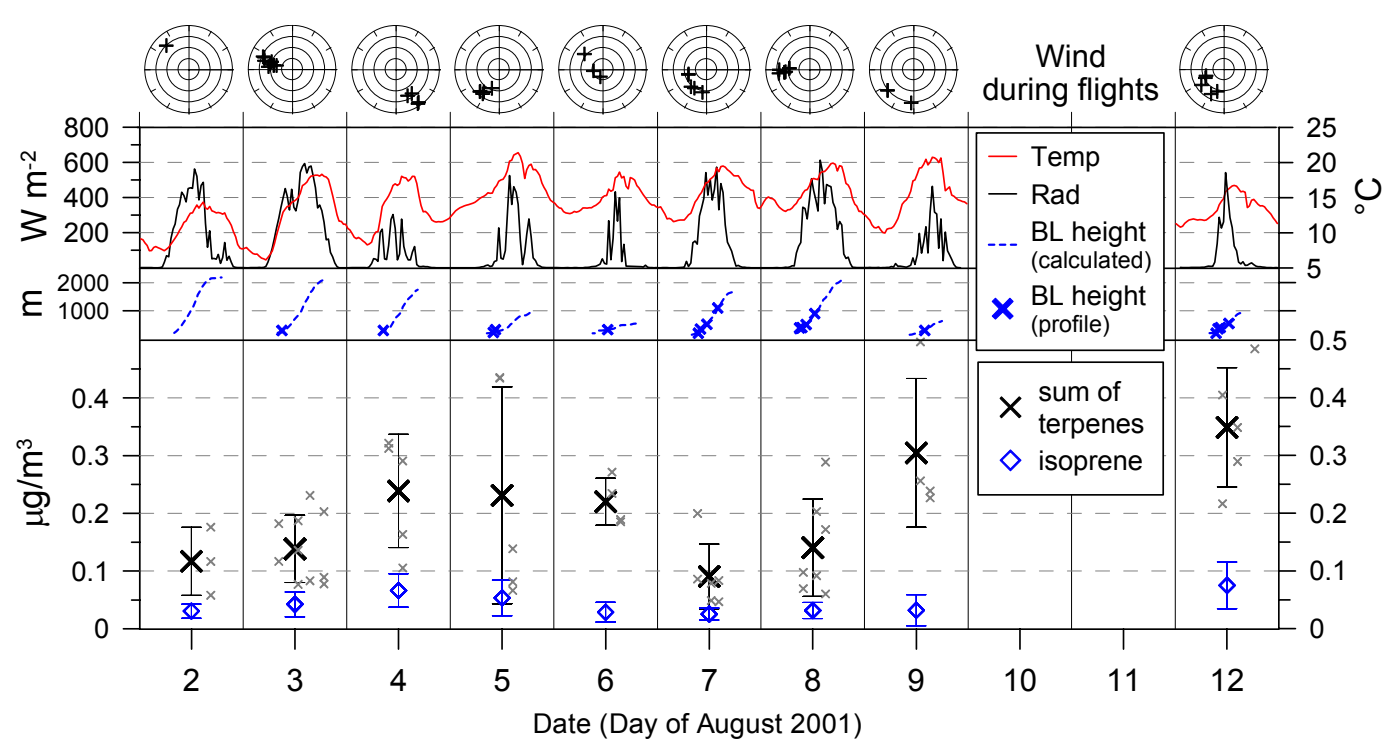

Fig. 2. Overview of mean mixed layer concentrations of biogenic VOCs (error bars are standard deviations) and meteorological conditions during the OSOA campaign at Hyytiälä. The angles of the polar plots correspond to wind directions, the radii to speeds (scale from 0 to $8 \mathrm{~ms}^{-1}$, spacing of concentric circles is $2 \mathrm{~ms}^{-1}$ ).

ground on the SMEAR II mast. Finally, the clear sky photolysis rates calculated by the model were scaled with help of UVA-measurements taken above the forest canopy.

\subsection{Footprint modelling}

Deriving fluxes from boundary layer measurements has the advantage of delivering estimates representative of large areas. Each of the methods we apply has its own area of influence. For concentration measurements, this area can be estimated from the footprint function. It can be understood as a probability function that describes how strongly an emission from a given elemental source downwind affects the measurement point (Fig. 1). The footprint of the MLG technique corresponds to the actual footprint of the profile measurements. Under strongly convective conditions with mean wind speeds up to $5 \mathrm{~ms}^{-1}$, it typically encompasses an upwind range of 0.2 to $10 \mathrm{~km}$, yielding footprint areas on the order of tens of square $\mathrm{km}$.

The fluxes derived by the MB technique are representative of even larger areas. For a given VOC, the upwind range of the footprint is approximately equal to the mean wind speed multiplied by the time required for this compound to reach a steady state concentration. For terpenoid compounds with usual lifetimes between $2-3 \mathrm{~h}$, this results in a footprint in the order of hundreds of square kilometres.

Spatial variation in surface emissions violates the assumptions of horizontal homogeneity in the boundary layer flux calculation methods. For the Hyytiälä site this may be an issue as the balloon launch site was located close to a lake. We therefore model the footprints of our profile measurements, for the purpose of determining the impact of heterogeneous surface emissions on the results of our flux estimates. The footprint model is described in detail by Kljun et al. (2002) and is based on a three-dimensional Lagrangian stochastic particle dispersion model (De Haan and Rotach, 1998). The model has been shown to produce valid footprint predictions under a wide range of stratifications and for receptors at heights from the surface to the mixed layer (Kljun et al., 2003).

\section{Results and Discussion}

\subsection{Balloon measurements}

From 2 August till 12 August 2001, we collected a total of 80 VOC samples from tethered balloons. Weather conditions were variable during this period, 3, 7, and 8 August were mostly sunny, other days were often cloudy and rainy. Operation of the balloon had to be interrupted several times by rain and high wind speeds that resulted in unsafe tethered balloon operating conditions.

Profiles of potential temperature $(\theta)$ and absolute humidity obtained from flights with continuous sampling during ascent and descent were used to determine the height of the convective boundary layer $\left(z_{i}\right)$. From plots of $\theta$ versus height, $z_{i}$ was chosen based on two criteria: 1) positive gradient $d \theta / d z$, 2 ) change in humidity with height. The measured profiles often showed several occurrences of positive temperature gradients. In such cases, the most pronounced $d \theta / d z$ with a coincident gradient in humidity was chosen as the indicator of the mixing layer height. The profile measurements by tethered balloons have the advantage of delivering at least 
Table 1. Average concentrations of biogenic VOCs at Hyytiälä and the ratios of their concentrations within (ML) and above the mixed layer (AML).

\begin{tabular}{|c|c|c|c|c|c|c|c|}
\hline & isoprene & $\alpha$-pinene & limonene & $\Delta^{3}$-carene & camphene & $\beta$-pinene & $\sum$ monoterp. \\
\hline \multicolumn{8}{|c|}{ Average concentrations in mixed layer, $\mu \mathrm{g} \mathrm{m}^{-3}$ (40 flights) } \\
\hline average & 0.041 & 0.079 & 0.049 & 0.041 & 0.02 & 0.015 & 0.26 \\
\hline $\begin{array}{l}\text { proportion of total } \\
\text { monoterpenes }\end{array}$ & $38 \%$ & $23 \%$ & $20 \%$ & $9 \%$ & $7 \%$ & & \\
\hline \multicolumn{8}{|c|}{ Concentration ratios within and above the mixed layer (ML/AML) (7 flights) } \\
\hline mean & 1.75 & 2.30 & 2.30 & 2.10 & 1.47 & 3.28 & 2.01 \\
\hline median & 0.93 & 1.57 & 1.87 & 1.98 & 1.29 & 1.45 & 1.77 \\
\hline interquartile range & $0.73-1.8$ & $1.39-2.97$ & $1.67-2.25$ & $1.69-2.52$ & $0.90-1.65$ & $0.93-2.67$ & $1.55-2.11$ \\
\hline
\end{tabular}

two temperature profiles per flight. The comparison of ascent and descent profiles allows an additional consistency check. Growth rates of the mixed layer were obtained from $z_{i}$ as determined from subsequent flights.

Some flights did not exceed the top of the boundary layer and their depths were estimated using the flux-ratio method (Stull, 2000). Continuous measurements of the surface heat flux on the tower and potential temperature differences across the boundary layer top as derived from balloon profiles early in the day were used to estimate $z_{i}$ using this method.

Figure 2 gives an overview on the meteorological conditions and averaged VOC concentrations in the mixed layer. The integrative VOC measurement during the ascent and descent of the balloon is considered as a representative sample of the mean boundary layer concentration. From three-levelprofiles, mean concentrations are derived by fitting the MLG profile to the three measurements and building the average over the whole profile. With our choice of heights for the three samplers, these mixed layer averages did not significantly differ from the arithmetic means of the measurements. Total monoterpene concentrations in the mixed layer during OSOA 2001 were of the order of $10-100 \mathrm{ppt}$, with $\alpha$-pinene $(38 \%)$, limonene $(23 \%), \Delta_{3}$-carene $(20 \%)$ and camphene $(9 \%)$ as the major compounds. Isoprene was also found in all samples, although at lower concentrations than the sum of monoterpenes.

Highest concentrations of biogenic VOCs were recorded on days with reduced radiation, apparently as a consequence of reduced vertical mixing and shallower boundary layer heights. Note however, that a day-by-day comparison of these concentrations is problematic as data coverage on single days varied significantly due to weather conditions. Winds were from a sector between 120 and 300 degrees during the balloon flights, at speeds up to $7 \mathrm{~ms}^{-1}$ (wind measurements at $50.9 \mathrm{~m}$ height on the tower). Maximum mixed layer heights varied between 1 and $2.2 \mathrm{~km}$ and were in agreement with results from earlier studies at Hyytiälä (Nilsson et al., 2001).

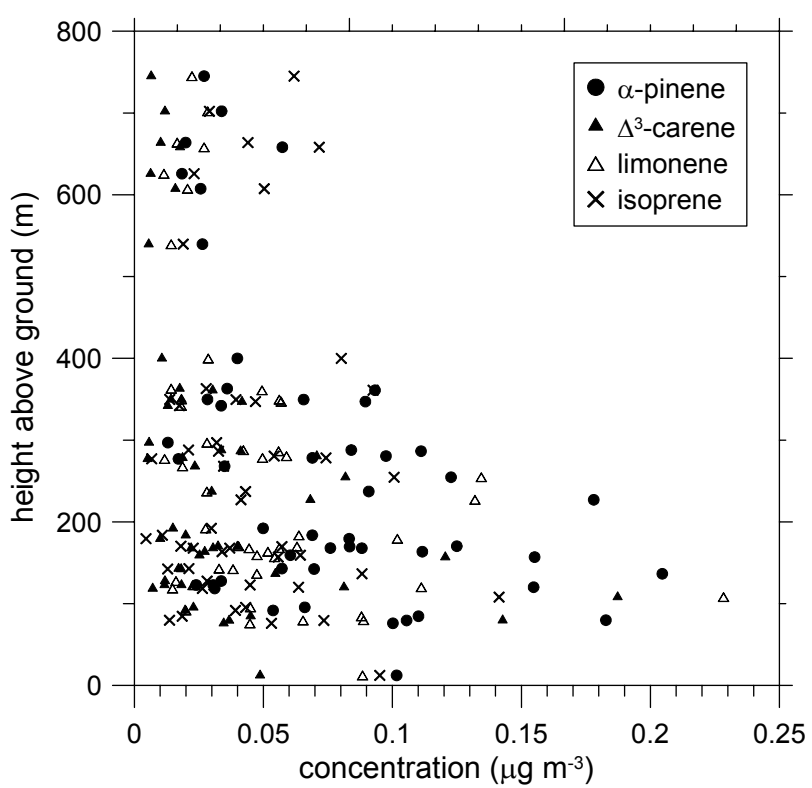

Fig. 3. Concentrations of major biogenic VOCs from 20 balloon profile measurements.

The concentration dependence with height above ground showed the expected behaviour for gases with a source at the surface. In general, concentrations decrease with height (Fig. 3). The maximum height of the uppermost samplers in our profile measurement was 600-750 m, whereas sample collection above the mixed layer was limited to situations with a shallow mixed layer, usually early in the day. Comparing the concentrations within and above the mixed layer from these flights (total of 7 profiles), the ratio of concentrations within the mixed layer (ML) and above the mixed layer (AML) was greater than one in nearly all cases for monoterpenes (Table 1). For isoprene, this trend was still observed in average, however with several inverse cases. Myrcene, tricyclene and sabinene were also detected in several samples, with greater concentrations in the mixed layer than 


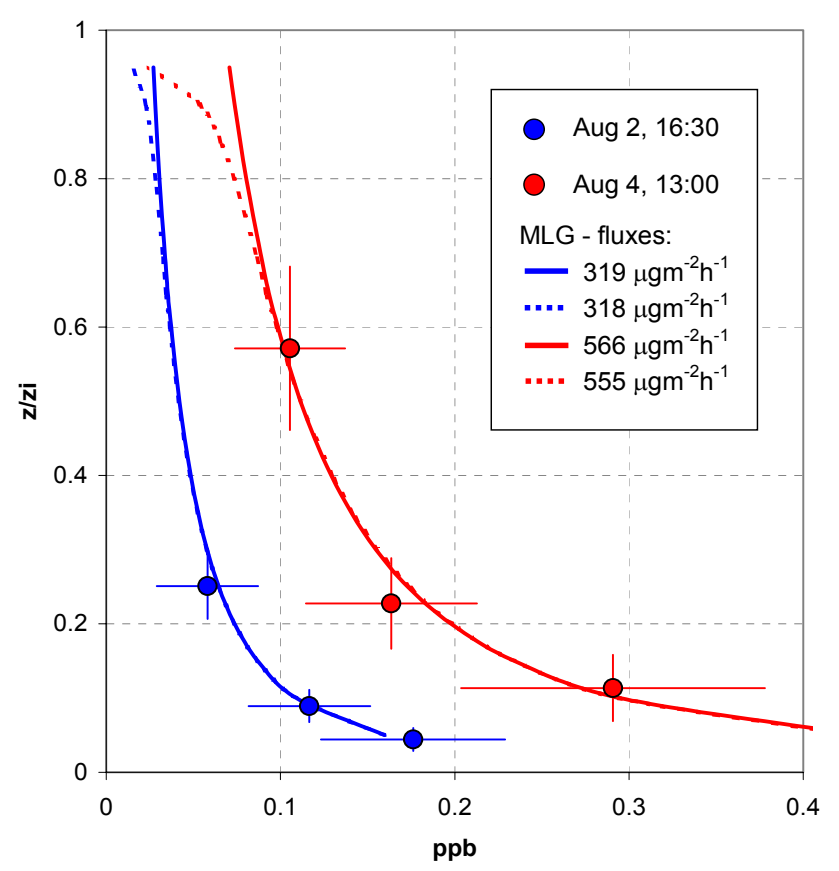

Fig. 4. Selected profiles of total monoterpene concentrations (symbols) and the corresponding fits as obtained by the MLG calculation. Solid lines are fits with entrainment fluxes set to zero, dotted lines are fits with entrainment fluxes estimated by the jump model.

above. The comparison of absolute concentrations within and above the mixed layer is more ambiguous, apparently as a consequence of large variations between concentrations of individual profiles and the limited number of flights exhibiting a VOC sample both below and above the mixed layer.

Earlier VOC studies in the area found $\alpha$-pinene, $\Delta^{3}$-carene and $\beta$-pinene as the dominating monoterpenes, limonene proportions were significantly lower than in our measurements. Based on leaf-level measurements of the dominating tree species in the area, Scots Pine and Norway Spruce (Komenda and Koppmann, 2002), limonene in such high proportions is surprising.

We considered the possibility of an analytical artefact in our VOC measurements. A general background problem is unlikely, as limonene concentrations correlated with those of the other monoterpenes. The use of KI traps for removal of ozone prior to sampling is known to produce artefacts (iodine-containing VOCs, though none shown to be derived from monoterpenes), but they can easily be distinguished from monoterpenes based on the EI-mass spectrum (Helmig and Greenberg, 1995). Finally, two VOC samples taken in parallel to our measurements, using different adsorbent media were analysed at CNR laboratories in Rome, Italy. The limonene concentrations determined there are consistent with the results of our measurements (Ciccioli et al., 2002). Limonene has also been detected in earlier measurements at this and other Boreal forest sites in Finland (Hakola et al.,
2000; Rinne et al., 2000). It has been shown that the composition of monoterpenes emitted by Scots Pine exhibits significant plant to plant variation and can also vary with season (Janson et al., 2001; Komenda and Koppmann, 2002). Results of a recent study (Hakola et al., 2003) on seasonal variations of monoterpene concentrations at Hyytiälä indicate that the proportions of limonene in emissions of Norway Spruce increase from early to late summer. Limonene has also been measured as a major compound emitted from soils (Hayward et al., 2001), and during decomposing of coniferous needles (Kainulainen and Holopainen, 2002). Finally, limonene concentrations are low enough to be caused by emissions from single plant species that may not be accounted for in the regional vegetation database. Given the lack of evidence for analytical artefacts and the above possibilities for the higher than expected limonene concentrations, we proceed with the measured concentrations in the following analyses.

\subsection{Flux estimates from mixed layer gradients}

As pointed out in Sect. 2.3.1, several conditions need to be fulfilled in order to derive fluxes from a gradient within the mixed layer. For compliance with sufficiently strong convective conditions, morning profiles before 1100 local time were excluded. From the remaining data set we also removed profiles with measurements exclusively above heights of $z / z_{i}=0.3$. The MLG equation predicts only small concentration differences associated with the surface flux at these heights. As a consequence, concentration gradients above this height do not contain sufficient information about the surface flux. After this screening, 12 profiles comprised of 32 individual VOC samples remained for flux calculations with the mixed layer gradient method.

The MLG equation was then fitted to the measured profiles, both with and without assumptions for entrainment fluxes. In the case of profiles with measurements at two levels only (4 out of 12 profiles), an assumption of the entrainment flux is required. In all cases, varying assumptions of entrainment fluxes did not result in significant differences of the surface fluxes (less than 10\%). This is not surprising, as we chose the concentration measurements at heights where gradients are influenced by the surface flux rather than the entrainment flux. Furthermore, our data selection includes midday to afternoon profiles exclusively, without cases of strong mixed layer growth, and concentration jumps across the boundary layer height were too small to result in significant entrainment fluxes. Figure 4 shows two exemplary profiles of total monoterpene concentrations and the corresponding fits from mixed layer gradient theory. For simplicity, the following analyses include only the results with entrainment fluxes set to zero.

Figure 5 shows the median fluxes of those VOC that were detected in every single measurement within the profiles. The median of the sum of monoterpene fluxes is $278 \mu \mathrm{g} \mathrm{m}^{-2} \mathrm{~h}^{-1}$. If the median terpene flux is calculated 


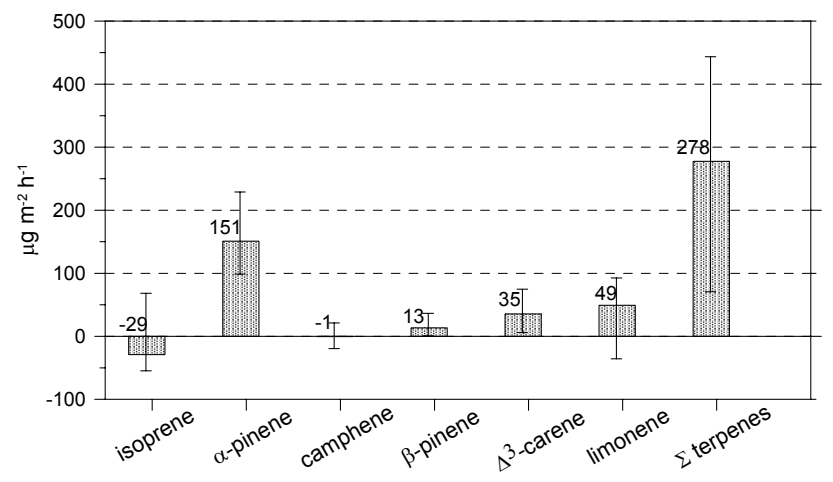

Fig. 5. Flux estimates from balloon profiles by the mixed layer gradient technique (medians, error bars are interquartile ranges).

from the gradients of total monoterpene concentrations of individual profiles, the resulting median flux of monoterpenes is $312 \mu \mathrm{g} \mathrm{m}^{-2} \mathrm{~h}^{-1}$. The higher number in the latter case is attributed to the very low concentrations of monoterpenes that could often be detected at the lowest altitude only and consequently overestimated the total monoterpene gradient. For isoprene, the MLG method derives a median deposition flux for this selection of profiles, while the average over the same data ensemble shows a small emission of $15 \mu \mathrm{g} \mathrm{m}^{-2} \mathrm{~h}^{-1}$.

As biogenic VOC emissions depend strongly on temperature, it is useful to normalize emission rates to a standard temperature. The temperature dependency of monoterpene emissions can be described by the equation

$$
E=E_{30} \cdot \exp \left[\beta\left(T-30^{\circ} C\right)\right],
$$

where $E_{30}$ is the emission rate normalized to $30^{\circ} \mathrm{C}, \beta$ is an empirical coefficient $(=0.09)$ and $T$ is temperature in degrees Celsius (Guenther et al., 1993). Normalizing the monoterpene fluxes to $30^{\circ} \mathrm{C}$ according to this algorithm yields an emission potential of 832-927 $\mu \mathrm{g} \mathrm{m}^{-2} \mathrm{~h}^{-1}$.

As documented by the large interquartile ranges, the variation of fluxes between individual profiles is considerable in spite of the preceding data selection. The following section addresses uncertainties and the effects of potential violations of the MLG assumptions in our flux calculations.

\subsubsection{Error and footprint discussion}

MLG estimates rely heavily on accurate measurements of mixing ratio differences. With the small VOC levels encountered at Hyytiälä, the differences for single monoterpene concentrations were close to the detection limit. The uncertainty of monoterpene measurements at these levels is estimated to be at least $\pm 30 \%$, propagating into large uncertainties of the flux estimates.

Non-homogeneity in surface emissions is one of the most common violations of the MLG assumptions in practice. Our balloon launch site was located close to a lake (Fig. 1) and often downwind of this lake during the measurement period.

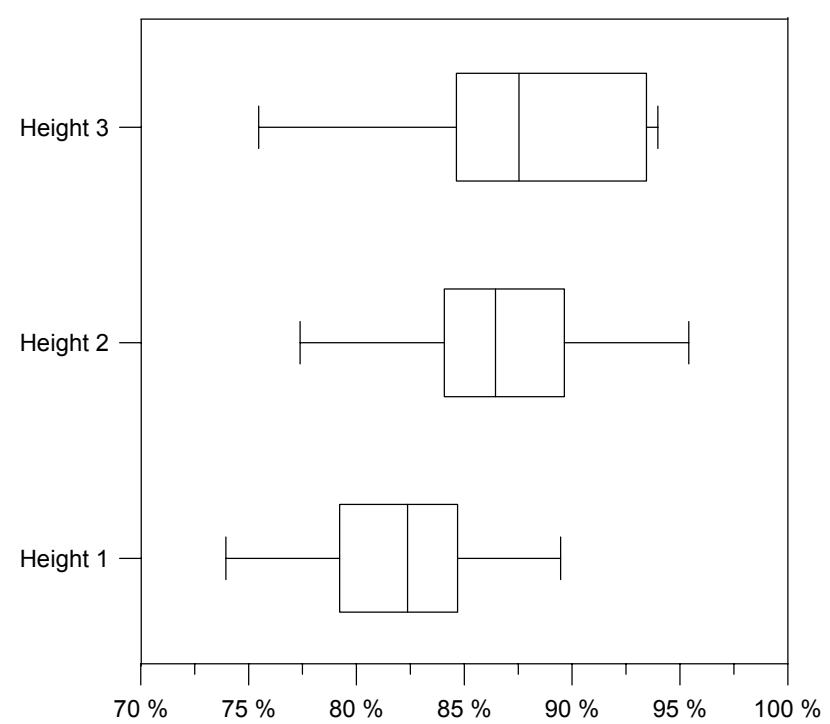

Fig. 6. Forest proportions in footprints of the balloon profiles (box plot with medians, quartiles and extremes), categorized by sampling levels; height $1=100-150 \mathrm{~m}$ above ground, height $2=250-350 \mathrm{~m}$, height $3=450-750 \mathrm{~m}$.

This severe inhomogeneity in surface emissions may influence our profiles. With the help of a footprint analysis, we evaluate how strongly the lake affects the flux estimates. The footprints of individual profile measurements are calculated with a footprint model (Sect. 2.5). By combining them with detailed land use data of $20 \times 20 \mathrm{~km}$ around the site, we assess differences in the source areas of individual profile measurements. The footprint model is run under the assumption of an infinite homogenous forest surface and a homogenous mean wind field.. The presence of the lake violates this assumption. During daytime, the lake is characterized by a lower surface temperature than the surrounding forest. This implies a stabilization of the boundary layer over the lake. Qualitatively, this means that the true footprint is located further upwind than simulated by the model, with the result that our simulations tend to overemphasize the importance of the surface elements close to the receptor, including the lake itself. In our effort to assess the impact of the nearby lake as a non-emitting spot within the source area, the model result therefore will reflect an upper limit estimate of its influence.

As an example for the model results, Fig. 1 illustrates the footprint of the measurement at $150 \mathrm{~m}$ on 3 August, 13:00 local time. Fetches for the profile measurements were calculated as the distance upwind where the crosswind-integrated footprint accumulates to $95 \%$. Typical fetches in the afternoon were 7 to $12 \mathrm{~km}$, yielding footprint areas on the order of 20 to $40 \mathrm{~km}^{2}$. With increasing measurement altitude, the fetches get larger and the maximum of the crosswindintegrated footprint function shifts further upwind. For measurements at $150 \mathrm{~m}$ above ground, the function peaks 


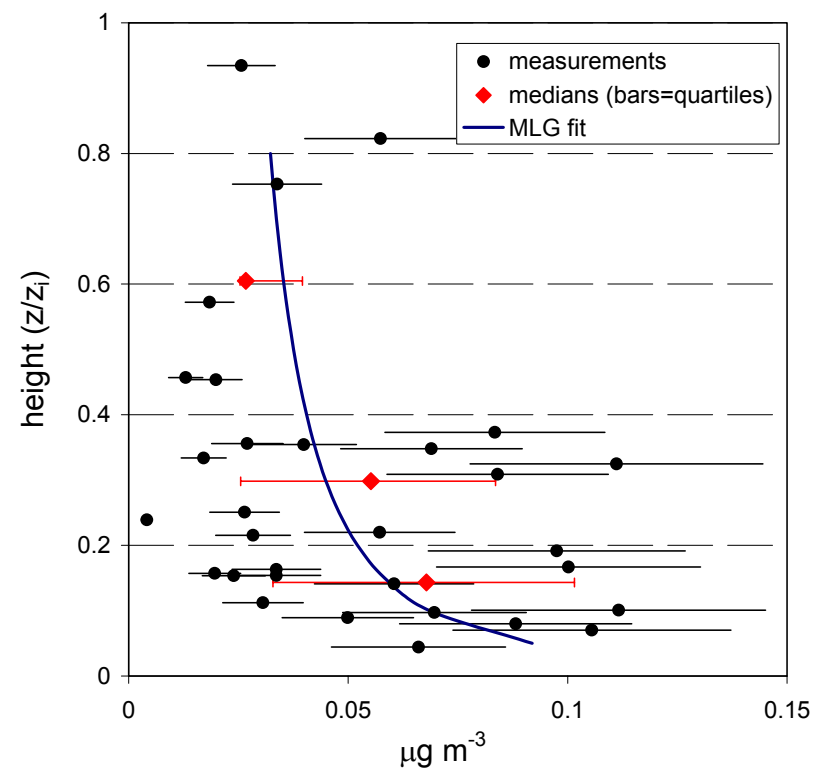

Fig. 7. Measurements of $\alpha$-pinene mixing ratios and predicted profile by the MLG equation for an $\alpha$-pinene surface emission of $130 \mu \mathrm{g} \mathrm{m}^{-2} \mathrm{~h}^{-1}$ and the median convective velocity scale $\left(1.7 \mathrm{~ms}^{-1}\right)$ of all profiles.

between 0.4 and $0.8 \mathrm{~km}$ upwind, the corresponding maxima for receptor heights around $600 \mathrm{~m}$ are less pronounced and occur at about $5 \mathrm{~km}$. As a consequence, the proportion of the nearby lake within the footprints is most pronounced for measurements at lower levels. Figure 6 is a box plot (medians, quartiles and extremes) showing the proportions of forested area within the footprints of the three sampling altitudes. The forest proportion is systematically smaller at the lowest measurement level. However, the variation of forest areas between different heights is within $15 \%$ of the average, a range considerably smaller than the error range due to the uncertainties in the concentration measurements.

A systematic error in the MLG calculations is introduced by neglecting chemical degradation. For very reactive VOCs like limonene and isoprene, chemical sinks are large enough to pronounce the vertical profile and the surface flux may be overestimated. In order to assess how strongly this accentuation of the gradient may influence the fluxes, we adjusted the profile concentrations to correct for chemical degradation. The concentration decrease at a certain height is approximated by the typical duration of vertical transport (height of measurement $/ w *$ ) times the total chemical loss rate of the VOC. The later was obtained from the photochemical model results (Sect. 3.3). Flux estimates from such modified profiles resulted in $5-15 \%$ lower fluxes in the median. Effects were most pronounced for limonene and only minor for other monoterpenes. The uncertainty associated with neglecting chemical sinks is therefore well within the overall uncertainties. Furthermore, this overestimate due to neglecting chem- istry approximately compensates for the potential underestimate due to the spatial inhomogeneities in emissions.

The MLG fluxes presented here were calculated with the original gradient functions (Moeng and Wyngaard, 1984; 1989), which neglect the effects of vegetation canopies on the vertical mixing of scalars. Calculations with the modified gradient function including the effect of canopies (Patton et al., 2003) resulted in higher fluxes, however the median of the total monoterpene fluxes is increased by only $10 \%$. This limited influence is attributed to the measurement heights of our profiles. They were typically at least $100 \mathrm{~m}$ above the canopy, where the modified gradient function deviates only slightly from the original function.

Some variability is introduced by calculating mean fluxes from individual profiles that were collected at differing temperatures and wind directions. Examining the rotation of selected footprints around the launch site, we conclude that the proportions of the forested surface do not vary by more than $15 \%$ for the wind directions observed during the campaign. Varying wind directions can therefore not explain the observed differences in fluxes. Surface temperatures during the selected profile measurements were also in a narrow range. With the exception of two profiles at $14^{\circ} \mathrm{C}$, surface temperatures were between 17.5 and $21.4^{\circ} \mathrm{C}$. As there is no evident correlation between fluxes from single profiles and corresponding temperatures, we acknowledge that other influences must dominate the overall variation.

An important issue violating the MLG assumption of a horizontally homogenous boundary layer is partial cloud cover. Most of the days within the OSOA campaign exhibited partly cloudy weather. It is impossible to quantify the error associated to variability in cloudiness, but it can be qualified as non-systematic.

Summarising this analysis, we conclude that systematic errors like the uncertainties as a consequence of footprint anomalies within single profiles or due to negligence of chemical degradation are small compared to non-systematic errors. These are dominated by uncertainties in the concentration measurements and by violations of the assumption of a horizontally homogenous boundary layer. Given that these errors are random in nature, the averaged monoterpene flux derived from the ensemble of profiles can be considered meaningful. On the other hand it is problematic to interpret fluxes from single profiles. The MLG method is not sensitive enough to determine the surface flux of isoprene or the emissions of single monoterpenes at this site, with the exception of $\alpha$-pinene. A plot of the MLG concentration profile for $\alpha$-pinene as predicted for the median flux from all individual profiles illustrates the large overall variation, but also the plausibility that the median flux lies within the observed concentrations of individual profiles (Fig. 7). 


\subsection{Fluxes from mixed box calculations}

While the MLG technique relies on theoretically firmer assumptions, flux estimates by the mass balance approach have the advantage of being based on the more robust measurement of mean mixed layer concentrations as compared to concentration differences from profile measurements. The balloon flights during OSOA delivered 40 mean mixed layer concentrations suitable for flux calculations with the mixed box technique. The median flux of total monoterpenes derived from these data is 100 and $186 \mu \mathrm{g} \mathrm{m}^{-2} \mathrm{~h}^{-1}$ for all measurements and the selection of afternoon data, respectively (Fig. 8). Normalized to $30^{\circ} \mathrm{C}$ (Eq. 8) the total monoterpene emissions are $575 \mu \mathrm{g} \mathrm{m}^{-2} \mathrm{~h}^{-1}$.

We first evaluate the magnitude of errors due to neglecting entrainment and horizontal advection in the MB approach. Mixed layer growth rates during the day were up to $0.05 \mathrm{~ms}^{-1}$, and the concentration difference of short-lived VOCs across the boundary layer top corresponds to the mean mixed layer concentrations, at most. This translates (Eq. 3) into a maximum entrainment rate of $35 \mu \mathrm{g} \mathrm{m}^{-2} \mathrm{~h}^{-1}$ for typical monoterpene concentrations $\left(0.19 \mu \mathrm{g} \mathrm{m}^{-3}\right)$ at Hyytiälä. While this may be a substantial fraction of the calculated surface flux during mixed layer growth before noon, the afternoon flux calculations are only slightly affected. The underestimate of MB fluxes due to the neglect of entrainment is therefore $20 \%$, at most.

Typical changes of mean monoterpene concentrations with time were $0 \pm 0.03 \mu \mathrm{g} \mathrm{h}^{-1}$. The random nature of these changes indicates that advection is dominating, but also supports that neglecting advection on average is reasonable (Eq. 4). From observed time changes of concentration and with typical mixed layer heights of $1500 \mathrm{~m}$, the uncertainty in box model surface flux estimates due to negligence of advection becomes $\pm 30 \mu \mathrm{g} \mathrm{m}^{-2} \mathrm{~h}^{-1}$.

The uncertainty in quantifying the chemical sink term in Eq. (6) usually dominates the overall uncertainty of box model flux estimates (Greenberg et al., 1999a). However, with the measurements of $\mathrm{NO}_{3}, \mathrm{O}_{3}$, VOCs and radiation available at Hyytiälä, it was possible to reasonably constrain the photochemical box model. The constraint of a box model representing the mixed layer with $\mathrm{O}_{3}$ and $\mathrm{NO}_{\mathrm{x}}$ measurements taken at the surface may be problematic in areas with strong local emissions of $\mathrm{NO}_{\mathrm{x}}$ (Spirig et al., 2002). At Hyytiälä however, there are no major $\mathrm{NO}_{\mathrm{x}}$ emissions upwind within several turnover times of the mixed layer, measurements were taken at $67 \mathrm{~m}$ above ground, reducing the influence of near-surface gradients.

Among the input data used for the photochemical box model, we consider the concentrations of VOCs other than biogenic compounds as those with the highest uncertainty. The sensitivity of the radical levels on anthropogenic VOC concentrations was evaluated by running the model with double and half anthropogenic VOC levels. The resulting maximum changes in $\mathrm{OH}$ levels at daytime were $-18 \%$ and

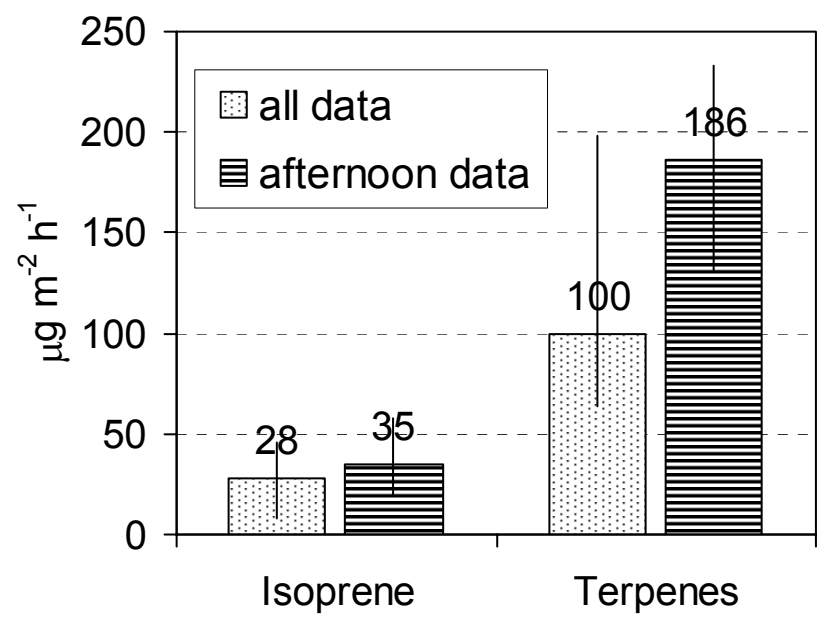

Fig. 8. Medians of surface fluxes as calculated by the MB technique during 2-12 August 2001, representing 40 individual data points. Error bars denote interquartile ranges.

$+13 \%$, for doubled and half anthropogenic VOC concentrations, respectively. This limited sensitivity is a consequence of the severe constraints with measurements, but also of the general characteristics of this rural site, which was not affected by significant pollution events during our measurements. We estimate the overall uncertainty for the quantification of the chemical loss rate for monoterpenes as $\pm 30 \%$. The determination of mixed layer heights from balloon profiles or estimates is associated with a $20 \%$ error. Assuming standard propagation of these errors in mixed layer depth and loss rate yields an uncertainty of $\pm 36 \%$.

Overall, the error range of the MB calculations is estimated to $\pm 50 \%$ for the averaged fluxes, and even higher for fluxes from single profiles, as a consequence of the influence of horizontal advection that accounts for an additional uncertainty of $20-30 \%$.

\subsection{Comparison of flux estimates}

The surface flux derived by the mixed box (MB) technique is lower on average than that calculated by the mixed layer gradient (MLG) method, even when the selection of MB fluxes is reduced to an ensemble comparable to that of the MLG estimates (encompassing fluxes after 1100 local time, exclusively).

The two techniques yield flux estimates representative for different areas. As calculated with the footprint model, fetches for the profile measurements and the MLG method were 7 to $12 \mathrm{~km}$, and footprints in the order of 30 to $50 \mathrm{~km}^{2}$. For comparison, the fetch of the MB technique can be estimated from the mean wind speed in the PBL times the lifetime of the substances. MB fetches for monoterpenes were between 50 and $100 \mathrm{~km}$, resulting in footprint areas of 200 to $500 \mathrm{~km}^{2}$ (assuming the same ratio of lateral and longitudinal 


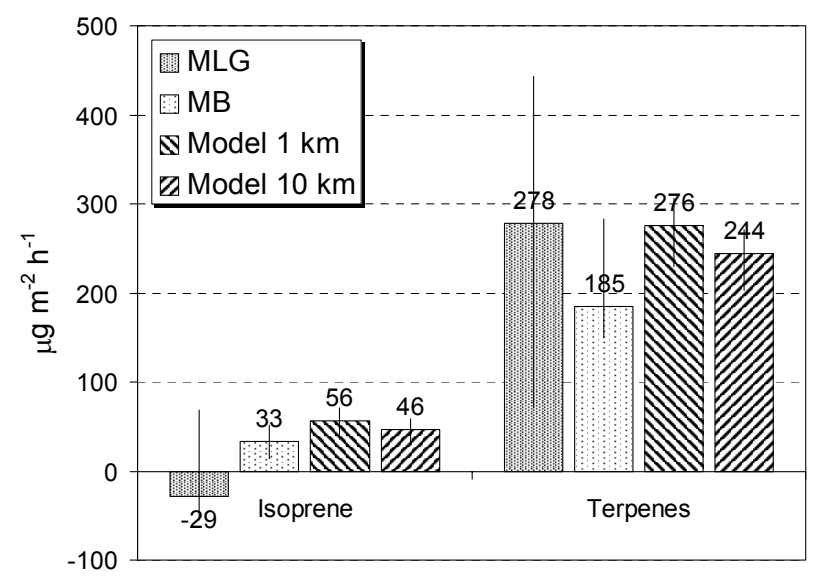

Fig. 9. Afternoon surface fluxes (medians) at Hyytiälä as derived from balloon profiles (MLG- and MB-technique) for 2-12 August 2001 and modelled biogenic VOC emissions (Lindfors et al., 2000) for areas of $1 \times 1 \mathrm{~km}$ and $10 \times 10 \mathrm{~km}$ around the site during the same period. Error bars are interquartile ranges.

dimension of the footprint as in the case of the modelled footprint functions). The different flux estimates from the two methods therefore indicate that monoterpene emissions close to the site are higher than the regional average.

Previous measurement efforts at Hyytiälä include the determination of fluxes with the surface layer gradient technique. Emissions derived from those measurements, representing the immediate surroundings of the SMEAR II tower, were between 200 and $450 \mu \mathrm{g} \mathrm{m}^{-2} \mathrm{~h}^{-1}$ for comparable temperature conditions in August 1998 (Rinne et al., 2000; Spanke et al., 2001). The fluxes derived by the MLG technique are in the same range, whereas the MB method with its significantly larger footprint observes a lower emission, again supporting our conclusion of lower emissions on regional scale.

Such a trend should also be reflected in the landcover data, so it is useful to look at modelled biogenic emissions for the Hyytiälä site. Lindfors et al. (2000) calculated biogenic emissions for European Boreal forests based on land cover information from satellite data and meteorological observations. Using the same emission model, terpene and isoprene emission rates were calculated for the areas $1 \times 1 \mathrm{~km}$ and $10 \times 10 \mathrm{~km}$ around the SMEAR II site. Figure 9 shows model emissions and the flux estimates from our balloon measurements. The selection of model data includes the emissions between 11 and 18 local time for 2-12 August. The larger of the model areas is comparable to the footprint size of the MLG technique, while the MB method estimates surface fluxes for even a larger area. On average, modelled and observationally derived emissions agree well. Furthermore, the trend of higher monoterpene emissions close to the site is also predicted in the emissions model. The trend of higher emissions near SMEAR II as compared to the regional aver- age is therefore in agreement with the landuse data around Hyytiälä.

Model and observations also agree for emissions of isoprene. As noted earlier, the MLG method proved not sensitive enough for the relatively low fluxes of isoprene, possibly because of rather inhomogeneous distribution of isoprene emissions within the mostly coniferous forest. For the budget technique with its larger footprint, this effect is of less importance. The isoprene fluxes from this method are similar to the model results.

\subsection{Production of condensable vapours}

The results of the photochemical modelling are also used to look at the monoterpene oxidation rates on different days. As terpene oxidation is considered to be an important source of condensable vapours, this analysis attempts to look at the links between monoterpene emissions and particle formation. Figure 10 shows the oxidation rates representing mean mixed layer conditions from 2-12 August for the days with VOC measurements from tethered balloons. Total oxidation rates (monoterpene+ $\mathrm{OH}-, \mathrm{O}_{3}-$, and $\mathrm{NO}_{3}$-reactions) as calculated with the photochemical model were between $1-8 \cdot 10^{5}$ molecules $\mathrm{cm}^{-3} \mathrm{~s}^{-1}$. The days with particle formation events (highlighted yellow in Fig. 10) exhibit rates of $2 \cdot 10^{5}$ molecules $\mathrm{cm}^{-3} \mathrm{~s}^{-1}$ or lower.

The oxidation products of monoterpenes are expected to partition between the gas and aerosol phase according to gas/particle partitioning theory (Odum et al., 1996). For the conditions at Hyytiälä with rather low amounts of pre-existing organic aerosol mass, an upper aerosol yield from monoterpene oxidation of $5 \%$ can be assumed. Using this fraction as an estimate for the amount of condensable products formed upon oxidation, the degradation of monoterpenes produces condensable compounds at a rate of $1 \cdot 10^{4}$ molecules $\mathrm{cm}^{-3} \mathrm{~s}^{-1}$ or less on days when particle formation was observed. This rate is close to the 1.2.10 $0^{4}$ molecules $\mathrm{cm}^{-3} \mathrm{~s}^{-1}$ found by Spanke et al. (2001), who derived this rate in a similar way from VOC measurements in August 1998 on the SMEAR II tower. A production of condensables on this order of magnitude is too low to explain the observed aerosol growth during those days. From aerosol size distribution measurements, the production of condensable vapours necessary to explain the observed growth of particles can be derived. For the particle formation events during the period of interest here, Boy et al. (2003) determined production rates of $1-2.6 \cdot 10^{5}$ molecules $\mathrm{cm}^{-3} \mathrm{~s}^{-1}$. Comparing these results from aerosol measurements with our calculations, at most $10 \%$ of the condensable vapours necessary to account for the newly formed aerosol could be explained by oxidation of monoterpenes.

However, our oxidation rates are representative for conditions within the mixed layer, whereas the amounts of condensable vapours were calculated from aerosol measurements at two metres above ground. Monoterpene 


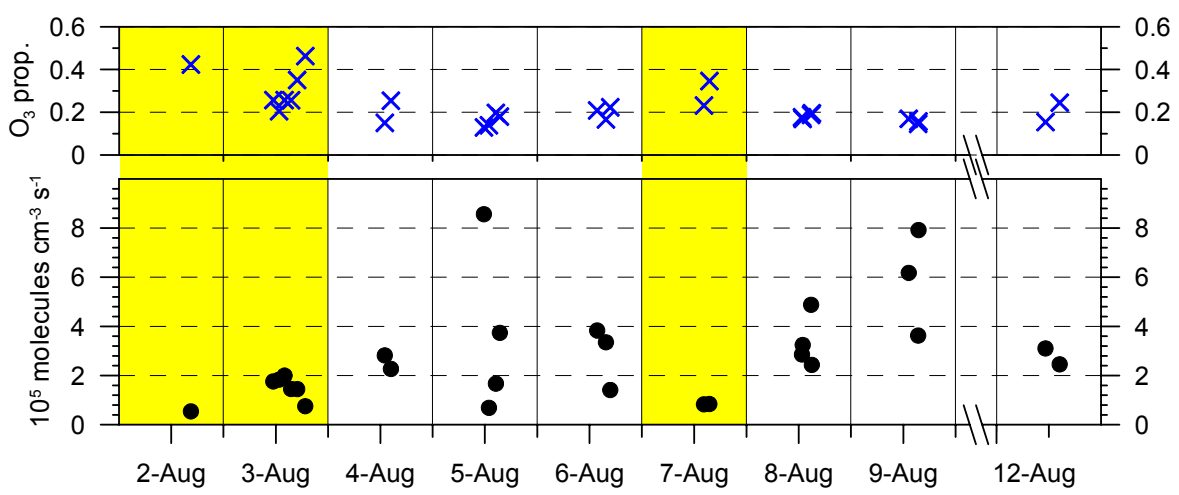

Fig. 10. Monoterpene oxidation rates, total oxidation rate (lower panel) and fraction of $\mathrm{O}_{3}$-pathway (upper panel) relative to the total rate. Days with observations of new particle formation are highlighted in yellow.

concentrations and oxidation rates close to the surface may be significantly higher than the average in the mixed layer. This was observed during a field campaign in 1998, where monoterpene oxidation rates derived from measurements at two metres height were found to be high enough to explain most of the observed aerosol growth (Janson et al., 2001). One might now speculate that particle production occurs mainly close to the surface. On the other hand, from all measurements carried out at Hyytiälä in 2001, including particle measurements throughout the mixed layer, there are no indications that particle formation would occur close to the surface exclusively. A definite answer can therefore not be given at this point, but these findings indicate that it would be valuable to have more vertically resolved measurements of particle distributions in the future.

Another aspect of biogenic VOC and particle formation is the question, if monoterpene oxidation products play a role in the nucleation process. In this perspective, we looked at the different oxidation pathways. Hoffmann et al. (1997), and Jang and Kamens (1999) showed that oxidation by ozone yields higher amounts of low volatility products than the reaction with $\mathrm{OH}$, and ozonolysis is considered to be the only pathway to generate nucleating species from monoterpene oxidation under atmospheric conditions (Bonn and Moortgat, 2002). The upper panel in Fig. 10 shows the relative contribution of the $\mathrm{O}_{3}$-pathway to the total oxidation rate. Because $\mathrm{OH}$ sources are mainly of photolytical origin, the relative importance of $\mathrm{O}_{3}$-oxidation exhibits a strong diurnal variation that is anti-correlated with radiation. For the purpose of the day-to-day comparison in Fig. 10, data points prior to 11 and later than $17 \mathrm{~h}$ local time were therefore excluded. It can be seen that the relative importance of the $\mathrm{O}_{3}$ channel tends to be higher on the days when new particle formations were observed. The same trend cannot be seen in the absolute amount of monoterpenes oxidized by $\mathrm{O}_{3}$, though, as a consequence of the lower concentrations of terpenes on event days. The trend of pronounced $\mathrm{O}_{3}$ oxidation on event days in a relative but not in an absolute way may be an indication that ozone-oxidation of VOCs not considered here could play an important role. Possible compounds include sesquiterpenes, biogenically emitted VOCs that are especially reactive with ozone and have very high yields of condensable vapours. Another possibility are components directly emitted from conifer leaf epicuticular wax, as recent analyses of organic aerosol matter in forested areas have shown significant contributions of such primary compounds (Kavouras and Stephanou, 2002).

\section{Conclusions}

Observations from tethered balloon platforms were used to derive monoterpene and isoprene fluxes on landscape scales around Hyytiälä for the period from 2-12 August 2001. The analysis of error sources in both methods revealed that the averaged surface fluxes derived from a number of profiles represent a robust order of magnitude estimate for regional emissions. On the other hand, flux estimates from single profiles are heavily influenced by non-systematic errors, especially for the low to moderate emission levels of individual compounds encountered at Hyytiälä. For these conditions, the methods are not useful for providing temporal resolution, but can characterize regionally averaged emissions.

Total monoterpene fluxes representative for areas of tens and hundreds square kilometres around Hyytiälä were 278 and $186 \mu \mathrm{g} \mathrm{m}^{-2} \mathrm{~h}^{-1}$, respectively, at a mean surface temperature of $17.5^{\circ} \mathrm{C}$. The mean level of biogenic VOC fluxes and the tendency of higher emissions close to the site are in agreement with the results of a biogenic VOC emission model. This gives confidence in the approaches of biogenic emission models that combine experimental information about emission rates of individual plants and regional landuse data to derive surface fluxes of large areas.

The links between biogenic VOC emissions and particle formation events remain ambiguous. Chemical analyses of aerosols clearly show a contribution of monoterpene 
oxidation products (Boy et al., 2003). On the other hand, our modelled oxidation rates of monoterpenes in the mixed layer are too low to account for the observed aerosol growth during the nucleation days alone, a significant fraction of condensing vapours needs to arise from a different source Possibilities include other biogenic VOC, such as sesquiterpenes, or direct biogenic particle emissions. Insufficient information about the vertical distribution of aerosols made it difficult to relate VOC measurements within the boundary layer to aerosol observations close to the surface. It would therefore be interesting to collect more information about the temporal evolution and the differences in aerosol and gas concentrations within the forest canopy and the layers above.

Future work on biogenic VOCs and aerosols should also include measurements of sesquiterpenes and oxygenated VOCs. However, the methods applied in this work cannot be used to estimate sesquiterpene fluxes from boundary layer measurements because of their short atmospheric lifetimes in the range of a few minutes.

Acknowledgements. The authors thank T. Pohja for his technical and logistic assistance at the Hyytiälä site. We are grateful to P. Aalto, M. Boy, M. Kulmala and P. Keronen of University of Helsinki for their support on the site and for providing us with landcover and measurement data of the SMEAR II site. Hal Westberg of Washington State University and Air Research Inc., Boulder CO (now Vaisala) each kindly lent us an electric winch. Christoph Spirig acknowledges funding through the Swiss National Science Foundation (Grant No. 21-61573.00). NCAR is sponsored by the National Science Foundation.

\section{References}

Aumont, B., Madronich, S., Ammann, M., Baltensperger, U., Hauglustaine, D., and Brocheton, F.: On the $\mathrm{NO}_{2}+$ soot reaction in the atmosphere, J. Geophys. Res., 104, 1729-1736, 1999.

Bonn, B. and Moortgat, G. K.: New particle formation during $\alpha$ and $\beta$-pinene oxidation by $\mathrm{O}_{3}, \mathrm{OH}$ and $\mathrm{NO}_{3}$, and the influence of water vapour: particle size distribution studies, Atmos. Chem. Phys., 2, 183-196, 2002.

Boy, M., Petäjä, T., Dal Maso, M., Rannik, Ü., Rinne, J., Aalto, P., Kulmala, M., Laaksonen, A., Joutsenaari, J., Hoffmann, T., Warnke, J., Apostolaki, M., Stephanou, E. G., Tsapakis, M., Kouvarakis, A., Pio, C., Carvalho, A., Römpp, A., Moortgat, G. K., Spirig, C., Guenther, A., Greenberg, J., and Ciccioli, P.: Overview of the field measurement campaign at Hyytiälä, August 2001 in the frame of the EU project OSOA, Atmos. Chem. Phys. Discuss., 3, 3769-3831, 2003.

Ciccioli, P., Possanzini, M., Brancaleoni, E., Frattoni, M., Di Palo, V., and Brachetti, A.: OSOA-Scientific Report of the second year, C.N.R., Roma, Italy, 2002.

Davis, K. J.: Surface fluxes of trace gases derived from convectivelayer profiles, Ph.D. thesis, University of Colorado, available as NCAR/CT-139 from NCAR, Boulder, CO, 1992.

Davis, K. J., Lenschow, D. H., and Zimmerman, P. R.: Biogenic nonmethane hydrocarbon emissions from tethered balloon observations, J. Geophys. Res., 99, 25 587-25 598, 1994.
Defries, R., Hansen, M., Townshend, J. R. G., Janetos, A. C., and Loveland, T. R.: A new global $1 \mathrm{~km}$ data set of percent tree cover derived from remote sensing, Global Change Biol., 6, 247-254, 2000.

De Haan, P. and Rotach, M. W.: A novel approach to atmospheric dispersion modelling: The Puff- Particle Model, Q. J. R. Meteorol. Soc., 124, 2771-2792, 1998.

Greenberg, J., Helmig, D., and Zimmerman, P.: Seasonal measurements of non-methane hydrocarbons and carbon monoxide at the Mauna Loa Observatory during the Mauna Loa Photochemistry Experiment 2, J. Geophys. Res., 101, 2721-2724, 1996.

Greenberg, J. P., Guenther, A., Zimmerman, P., Baugh, W., Geron, C., Davis, K., Helmig, D., and Klinger, L. F.: Tethered balloon measurements of biogenic VOCs in the atmospheric boundary layer, Atmos. Environ., 33, 855-867, 1999a.

Greenberg, J. P., Guenther, A. B., Madronich, S., Baugh, W., Ginoux, P., Druilhet, A., Delmas, R., and Delon, C.: Biogenic volatile organic compound emissions in central Africa during the Experiment for the Regional Sources and Sinks of Oxidants (EXPRESSO) biomass burning season, J. Geophys. Res., 104, 30 659-30671, 1999b.

Greenberg, J. P., Guenther, A. B., Pétron, G., Wiedinmyer, C., Vega, O., V. Gatti, L., Tota, J., and Fisch, G.: Biogenic VOC emissions from forested Amazonian landscapes, Global Change Biol., in press, 2004.

Griffin, R., Cocker, D., Seinfeld, J., and Dabdub, D.: Estimate of global atmospheric organic aerosol from oxidation of biogenic hydrocarbons, Geophys. Res. Letters, 26, 2721-2724, 1999.

Guenther, A., Zimmerman, P., Harley, P., Monson, R., and Fall, R.: Isoprene and monoterpene emission rate variability: Model evaluation and sensitivity analysis, J. Geophys. Res., 98, 12 609$12617,1993$.

Guenther, A., Zimmerman, P., Klinger, L., Greenberg, J., Ennis, C., Davis, K., Pollock, W., Westberg, H., Allwine, E., and Geron, C.: Estimates of regional natural volatile organic compound fluxes from enclosure and ambient measurements, J. Geophys. Res., 101, 1345-1359, 1996.

Hakola, H., Laurila, T., Rinne, J., and Puhto, K.: The ambient concentrations of biogenic hydrocarbons at a northern European, boreal site, Atmos. Environ., 34, 4971-4982, 2000.

Hakola, H., Tarvainen, V., Laurila, T., Hiltunen, V., Hellen, H., and Keronen, P.: Seasonal variation of VOC concentrations above a boreal coniferous forest, Atmos. Environ., 37, 1623-1634, 2003.

Hansen, M., DeFries, R., Townshend, J. R. G. and Sohlberg, R.: Global land cover classification at $1 \mathrm{~km}$ resolution using a decision tree classifier, Int. J. of Remote Sensing, 21, 1331-1365, 2000.

Hauglustaine, D. A., Madronich, S., Ridley, B. A., Flocke, S. J., Cantrell, C. A., Eisele, F. L., Shetter, R. E., Tanner, D. J., and Ginoux, P.: Photochemistry and budget of ozone during the Mauna Loa Observatory Photochemistry Experiment (MLOPEX 2), J. Geophys. Res., 104, 30 275-30 307, 1999.

Hayward, S., Muncey, R. J., James, A. E., Halsall, C. J., and Hewitt, C. N.: Monoterpene emissions from soil in a Sitka spruce forest, Atmos. Environ., 35, 4081-4087, 2001.

Helmig, D.: Ozone removal techniques in the sampling of atmospheric volatile organic trace gases, Atmos. Environ., 31, 36353651, 1997. 
Helmig, D., Balsley, B., Davis, K., Kuck, L. R., Jensen, M., Bognar, J., Smith, T., Arrieta, R. V., Rodriguez, R., and Birks, J. W.: Vertical profiling and determination of landscape fluxes of biogenic nonmethane hydrocarbons within the planetary boundary layer in the Peruvian Amazon, J. Geophys. Res., 103, 25 519-25 532, 1998.

Helmig, D. and Greenberg, J.: Artifact Formation from the Use of Potassium-Iodide-Based Ozone Traps During Atmospheric Sampling of Trace Organic Gases, J. High Res. Chromatogr., 18, 1518, 1995.

Hoffmann, T., Odum, J. R., Bowman, F., Collins, D., Klockow, D., Flagan, R. C., and Seinfeld, J. H.: Formation of organic aerosols from the oxidation of biogenic hydrocarbons, J. Atmos. Chem., 26, 189-222, 1997.

Jang, M. and Kamens, R. M.: Newly characterized products and composition of secondary aerosols from the reaction of $\alpha$-pinene with ozone, Atmos. Environ., 33, 459-474, 1999.

Janson, R., Rosman, K., Karlsson, A., and Hansson, H. C.: Biogenic emissions and gaseous precursors to forest aerosols, Tellus B, 53, 423-440, 2001.

Kainulainen, P. and Holopainen, J. K.: Concentrations of secondary compounds in Scots pine needles at different stages of decomposition, Soil Biol. Biochem., 34, 37-42, 2002.

Kamens, R., Jang, M., Chien, C.-J., and Leach, K.: Aerosol formation from the reaction of $\alpha$-pinene and ozone using a gas-phase kinetics-aerosol partitioning model, Environ. Sci. Technol., 33, 1430-1438, 1999.

Karl, T. G., Spirig, C., Rinne, J., Stroud, C., Prevost, P., Greenberg, J., Fall, R., and Guenther, A.: Virtual disjunct eddy covariance measurements of organic compound fluxes from a subalpine forest using proton transfer reaction mass spectrometry, Atmos. Chem. Phys., 2, 279-291, 2002.

Kavouras, I., Mihalopoulos, N., and Stephanou, E.: Formation of atmospheric particles from organic acids produced by forests, Nature, 395, 683-686, 1998.

Kavouras, I., Mihalopoulos, N., and Stephanou, E.: Secondary organic aerosol formation vs primary organic aerosol emission: In situ evidence for the chemical coupling between monoterpene acidic photooxidation products and new particle formation over forests, Environ. Sci. Technol., 33, 1028-1037, 1999.

Kavouras, I. G. and Stephanou, E. G.: Direct Evidence of Atmospheric Secondary Organic Aerosol Formation in Forest Atmosphere through Hetermomolecular Nucleation, Environ. Sci. Technol., 36, 5083-5091, 2002.

Kljun, N., Kormann, R., Rotach, M. W., and Meixer, F. X.: Comparison of the Langrangian footprint model LPDM-B with an analytical footprint model, Bound.-Layer Meteor., 106, 349-355, 2003.

Kljun, N., Rotach, M. W., and Schmid, H. P.: A three-dimensional backward lagrangian footprint model for a wide range of boundary-layer stratifications, Bound.-Layer Meteor., 103, 205226, 2002.

Komenda, M. and Koppmann, R.: Monoterpene emissions from Scots pine (Pinus sylvestris): Field studies of emission rate variabilities, J. Geophys. Res., 107, 10.1029/2001JD000691, 2002.
Kulmala, M., Hameri, K., Aalto, P. P., Makela, J. M., Pirjola, L., Nilsson, E. D., Buzorius, G., Rannik, U., Dal Maso, M., Seidl, W., Hoffman, T., Janson, R., Hansson, H. C., Viisanen, Y., Laaksonen, A., and O'Dowd, C. D.: Overview of the international project on biogenic aerosol formation in the boreal forest (BIOFOR), Tellus B, 53, 324-343, 2001.

Leaitch, W. R., Bottenheim, J. W., Biesenthal, T. A., Li, S. M., Liu, P. S. K., Asalian, K., Dryfhout-Clark, H., Hopper, F., and Brechtel, F.: A case study of gas-to-particle conversion in an eastern Canadian forest, J. Geophys. Res., 104, 8095-8111, 1999.

Lindfors, V., Laurila, T., Hakola, H., Steinbrecher, R., and Rinne, J.: Modeling speciated terpenoid emissions from the European boreal forest, Atmos. Environ., 34, 4983-4996, 2000.

Madronich, S. and Flocke, S.: The role of solar radiation in atmospheric chemistry, in The Handbook of Environmental Chemistry, edited by Boule, P., pp. 1-26, Springer-Verlag Berlin Heidelberg New York, Berlin, 1999.

Mäkelä, J. M., Aalto, P., Jokinen, V., Pohja, T., Nissinen, A., Palmroth, S., Markkanen, T., Seitsonen, K., Lihavainen, H., and Kulmala, M.: Observations of ultrafine aerosol particle formation and growth in boreal forest, Geophys. Res. Letters, 24, 1219$1222,1997$.

Moeng, C. H. and Wyngaard, J. C.: Statistics of Conservative Scalars in the Convective Boundary- Layer, J. Atmos. Sci., 41, 3161-3169, 1984

Moeng, C. H. and Wyngaard, J. C.: Evaluation of Turbulent Transport and Dissipation Closures in 2nd-Order Modeling, J. Atmos. Sci., 46, 2311-2330, 1989.

Nilsson, E. D., Paatero, J., and Boy, M.: Effects of air masses and synoptic weather on aerosol formation in the continental boundary layer, Tellus B, 53, 462-478, 2001.

Patton, E. G., Sullivan, P. P., and Davis, K. J.: The influence of a forest canopy on top-down and bottom-up diffusion in the planetary boundary layer, Q. J. R. Meteorol. Soc., 129, 1415-1434, 2003.

Odum, J. R., Hoffmann, T., Bowman, F., Collins, D., Flagan, R. C., and Seinfeld, J. H.: Gas/particle partitioning and secondary organic aerosol yields, Environ. Sci. Technol., 30, 2580-2585, 1996.

Rinne, J., Hakola, H., Laurila, T., and Rannik, Ü. Canopy scale monoterpene emissions of Pinus sylvestris dominated forests, Atmos. Environ., 34, 1099-1107, 2000.

Spanke, J., Rannik, Ü., Forkel, R., Nigge, W., and Hoffmann, T.: Emission fluxes and atmospheric degradation of monoterpenes above a boreal forest: field measurements and modelling, Tellus, 53B, 406-422, 2001.

Spirig, C., Neftel, A., Kleinman, L. I., and Hjorth, J.: $\mathrm{NO}_{\mathrm{x}}$ versus VOC limitation of $\mathrm{O}_{3}$ production in the Po valley: Local and integrated view based on observations, J. Geophys. Res., 107, 8191, 10.1029/2001JD000561, 2002.

Stull, R. B.: Meteorology for scientists and engineers, 502 pp., Brooks/Cole, Pacific Grove CA, 2000.

Wyngaard, J. C. and Brost, R. A.: Top-Down and Bottom-up Diffusion of a Scalar in the Convective Boundary-Layer, J. Atmos. Sci., 41, 102-112, 1984. 